\title{
CARACTERIZAÇÃO DA PRODUÇÃO DE CAPIM-LIMÃO NO ESTADO DO PARANÁ, BRASIL'
}

\section{CHARACTERIZATION OF THE LEMON-GRASS PRODUCTION IN THE PARANÁ STATE, BRAZIL}

\author{
Eliane Carneiro GOMES ${ }^{2}$ \\ Raquel Rejane Bonato NEGRELLE ${ }^{3}$ \\ Luiz DONI FILHO4
}

\begin{abstract}
RESUMO
Dada à importância do capim-limão (Cymbopogon citratus (D.C.) Stapf) no âmbito da produção estadual de produtos especiais (plantas medicinais, especiarias e afins), apresenta-se resultado de pesquisa que visou caracterizar os procedimentos associados à produção desta espécie no Estado do Paraná, evidenciando as congruências e incongruências dos dados registrados em campo comparativamente aos já descritos na literatura como adequados para este tipo de cultura. Os principais problemas evidenciados relacionavam-se ao desconhecimento por parte dos produtores quanto a vários de aspectos relacionados a esta cultura, englobando a obtenção adequada de mudas, época adequada de plantio e de colheita para maximização de biomassa e do teor de princípios ativos, controle de pragas e doenças, associados à prática de cultura orgânica sob supervisão técnica. Avalia-se como imprescindível, a urgente transferência de informações técnicas aos produtores, incluindo aquelas relativas à aplicação de boas práticas agrícolas na cultura do capim-limão.
\end{abstract}

Palavras-chave: cultivo; tratos culturais; manejo de cultura; assistência técnica.

\begin{abstract}
Considering the importance of lemon-grass (Cymbopogon citratus (D.C.) Stapf) crop on the special products sector (medicinal plants, species and similars) of Paraná State (Southern Brazil), this work presents a characterization of the Parana lemongrass production evidencing the congruence and incongruity of the observed procedures taking into consideration what is reported on literature as being proper for this crop. The main problems evidenced were linked with ignorance of the producers about many proper aspects related with the crop, including seedlings production/ obtaining; ideal time for plantation and harvesting to maximize biomass and quantity of active substances; control of plagues and diseases and, organic practices. The urgent need of transference of technical information to producers, including those relating to application of good agricultural practices of lemon grass crop was evidenced.
\end{abstract}

Key-words: cultivation; crop procedures; crop management; technical assistance.

\footnotetext{
${ }^{1}$ Parte da tese de Doutorado do primeiro autor, área de Agronomia - Produção Vegetal, apresentada à Universidade Federal do Paraná, em 2003. ${ }^{2}$ Farmacêutica-Bioquímica, Dr. Agronomia- Produção Vegetal, Laboratórios de Saúde Ambiental e Saúde Pública, Prof. Dep. Saúde Comunitária - UFPR, Rua Padre Camargo, 280. Alto da Glória, Curitiba, PR, 80060-240. E-mail: elianegomes@ufpr.br. Autor para correspondência. ${ }^{3}$ Bióloga, Dr. Ecologia e Recursos Naturais, Lab.OIKOS, Departamento de Botânica - UFPR. Cx.Postal 19031. 81531-970 Curitiba, PR. E-mail: negrelle@ufpr.br.

${ }^{4}$ Eng.Agrônomo, Dr. Agronomia, Departamento de Fitotecnia e Fitossanitarismo - UFPR. E-mail: doni@ufpr.
} 


\section{INTRODUÇÃO}

O capim-limão (Cymbopogon citratus (D.C.) Stapf) é cultivado em praticamente em todos os países tropicais. No Brasil, a produção desta espécie ocorre destacadamente nas Regiões Sul e Sudeste. No Estado do Paraná, maior produtor de plantas medicinais aromáticas do País, a produção de capimlimão ocupa posição de destaque. A safra -2003/2004 totalizou 1108,6 t, ocupando 39,1 ha distribuídos em vinte e um municípios produtores. $\mathrm{O}$ valor bruto da produção agrícola desta safra totalizou $R \$$ $443.456,12$. Estas cifras levaram este produto a ser classificado como um dos "produtos especiais" mais valorizados no Paraná (PARANÁ, 2005). Nos segmentos industrial e supermercadista na região Sul, especialmente na cidade de Curitiba, o chá de capim-limão, tem sido apontado como um dos principais chás comercializados pelas empresas do ramo (GOMES, 2003).

Assim, dada à importância do capim-limão no âmbito da produção de produtos especiais (plantas medicinais, especiarias e afins), apresenta-se resultado de pesquisa que visou caracterizar os procedimentos associados à produção do capimlimão no Estado do Paraná, evidenciando as congruências e divergências dos dados registrados em campo comparativamente aos já descritos na literatura como adequados para este tipo de cultura.

\section{MATERIAL E MÉTODOS}

Executou-se pesquisa exploratóriodescritiva, baseada em levantamento bibliográfico e documental e na aplicação de questionários e entrevistas (abril a novembro / 2000). O universo de entrevistados englobou 13 técnicos extensionistas de nível superior da Secretaria de Agricultura e Abastecimento do Estado do Paraná - SEAB/PR e da Empresa Paranaense de Assistência Técnica e Extensão Rural - EMATER /PR, além de 22 produtores agrícolas e/ou agroindustriais representando oito Núcleos Regionais Administrativos (NRA) Produtores do Estado. Estas pessoas foram entrevistadas, com a finalidade de caracterizar o perfil tecnológico e a qualidade higiênico-sanitária do cultivo de capim-limão no Estado do Paraná. Os aspectos avaliados foram: método de obtenção de mudas, modo de preparo do solo, época de plantio, espaçamento, adubação, tratos culturais, técnica de colheita, parte colhida, rendimento, forma de irrigação, incidência de pragas e doenças. Adicionalmente, realizou-se exame nematológico no solo e em raízes de plantas cultivadas em um dos Núcleos Regionais, no sentido de averiguar um possível ataque explicitado pelos produtores. Estas análises foram efetuadas pelo Centro de Diagnóstico Marcos Enrietti vinculado à SEAB-PR, seguindo padrões usuais.

\section{RESULTADOS E DISCUSSÃO}

\section{Obtenção de mudas}

O capim-limão é uma planta que somente produz sementes quando cultivada em clima tropical e se não for submetida à colheita por vários anos (ORTIZ et al., 2002). Em situações de clima desfavorável e sob pressão de colheita, usualmente propaga-se vegetativamente, por meio de perfilhos, que crescem ao redor das plantas adultas (ACOSTA DE LA LUZ, 1993). Neste caso, cada perfilho é utilizado como muda, devendo-se, no momento do plantio, cortar as folhas rente à inserção da bainha e evitar dessecação das raízes de modo a otimizar o pegamento (SILVA JÚNIOR et al., 1994; CASTRO e CHEMALE, 1995; EVENTO, 2000).

$\mathrm{Na}$ região da pesquisa de campo, não há registro de produção de sementes de capim-limão. Constatou-se que em sete dos oito núcleos produtores de capim-limão, a obtenção das mudas (perfilhos) ocorria por ações extrativistas, em touceiras à beira de estradas onde a espécie cresce espontaneamente (Tabela 1). Este procedimento gera mudas sem qualidade e potencialmente contaminadas, principalmente por poluentes, como metais pesados, lançados pelos veículos. A dificuldade da obtenção de mudas de qualidade e o alto custo destas foram justificativas apresentadas pelos produtores para o procedimento extrativista. Apenas no Núcleo de Jacarezinho foi registrada a existência de estufas para produção de mudas por perfilho, sob orientação agronômica. 
GOMES, E.C. et al. Caracterização da produção de capim-limão...

TABELA 1 - Aspectos do cultivo do capim-limão nos Núcleos Regionais Administrativos (NRA) da Secretaria de Agricultura e Abastecimento do Estado do Paraná (SEAB-PR), 2000.

\begin{tabular}{|c|c|c|c|c|c|c|c|c|}
\hline \multirow{2}{*}{$\begin{array}{l}\text { Detalhes da } \\
\text { produção }\end{array}$} & \multicolumn{8}{|c|}{ Núcleos Regionais Administrativos da SEAB/PR } \\
\hline & Apucarana & Cascavel & Curitiba & $\begin{array}{c}\text { Francisco } \\
\text { Beltrão }\end{array}$ & Guarapuava & Irati & Ivaiporã & Jacarezinho \\
\hline $\begin{array}{l}\text { Número de } \\
\text { produtores }\end{array}$ & 7 & 9 & 16 & $\mathrm{ni}^{*}$ & 137 & 4 & 71 & 2 \\
\hline $\begin{array}{l}\text { Obtenção } \\
\text { de mudas }\end{array}$ & \multicolumn{7}{|c|}{ Extrativismo/perfilhos } & $\begin{array}{c}\text { Estufa de } \\
\text { propagação } \\
\text { vegetativa }\end{array}$ \\
\hline $\begin{array}{l}\text { Preparo do } \\
\text { solo }\end{array}$ & Manual & $\begin{array}{l}\text { Maioria } \\
\text { manual }\end{array}$ & Manual & $\begin{array}{l}\text { Maioria } \\
\text { manual }\end{array}$ & \multicolumn{3}{|c|}{ Manual } & Mecanizado \\
\hline $\begin{array}{l}\text { Análise de } \\
\text { solo antes } \\
\text { do plantio }\end{array}$ & ni & $\begin{array}{l}\text { Alguns } \\
\text { realizam }\end{array}$ & não & ni & ni & não & ni & não \\
\hline $\begin{array}{l}\text { Época de } \\
\text { plantio }\end{array}$ & $\begin{array}{c}\text { De acordo } \\
\text { com a } \\
\text { demanda }\end{array}$ & \multicolumn{5}{|c|}{ Agosto a dezembro } & $\begin{array}{l}\text { Conforme } \\
\text { obtenção } \\
\text { de mudas }\end{array}$ & $\begin{array}{l}\text { Agosto a } \\
\text { dezembro }\end{array}$ \\
\hline $\begin{array}{l}\text { Espaça- } \\
\text { mento }\end{array}$ & \multicolumn{8}{|c|}{ Sulcos eqüidistantes 0,50 a $0,80 \mathrm{~m}$; perfilhos eqüidistantes $0,50 \mathrm{~m} ; 30$ a 40 mil muda ha ${ }^{-1}$} \\
\hline Adubação & \multicolumn{6}{|c|}{$\begin{array}{l}\text { Orgânica não sistemática. Na regional de Cascavel alternativamente é } \\
\text { utilizado o esterco de aviário ( } 4 \mathrm{t} \mathrm{ha}^{-1} \text { uma vez ao ano) }\end{array}$} & \multicolumn{2}{|c|}{ Não adubam } \\
\hline $\begin{array}{l}\text { Tratos } \\
\text { culturais }\end{array}$ & \multicolumn{8}{|c|}{$\begin{array}{l}\text { Eliminação de ervas daninhas manual e não sistemática. } \\
\text { Nenhum dos entrevistados admitiu utilizar herbicidas }\end{array}$} \\
\hline Colheita & \multicolumn{8}{|c|}{$\begin{array}{l}\text { Corte manual a } 20 \mathrm{~cm} \text { do solo. Primeira colheita } 4 \text { a } 8 \text { meses após o plantio. } \\
\text { Demais colheitas } 2 \text { a } 5 \text { vezes ao ano }\end{array}$} \\
\hline Irrigação & \multicolumn{8}{|c|}{ Não irrigado } \\
\hline $\begin{array}{ll}\text { Pragas } & \text { e } \\
\text { doenças }\end{array}$ & \multicolumn{2}{|c|}{ Doenças fúngicas } & $\begin{array}{l}\text { Não } \\
\text { ocorrem }\end{array}$ & \multicolumn{2}{|c|}{ Doenças fúngicas } & $\begin{array}{c}\text { Não } \\
\text { ocorrem }\end{array}$ & \multicolumn{2}{|c|}{ Doenças fúngicas } \\
\hline $\begin{array}{l}\text { Parte } \\
\text { colhida }\end{array}$ & \multicolumn{8}{|c|}{ Folhas } \\
\hline Rendimento & ni & $\begin{array}{l}\text { 16-26 } \\
\text { t ha }^{-1}\end{array}$ & & ni & $\begin{array}{c}7,5 \\
\text { t ha }^{-1}\end{array}$ & ni & $\begin{array}{l}7-10 \\
\text { t ha }^{-1}\end{array}$ & $\begin{array}{c}40 \\
\mathrm{~kg} \text { óleo ha-1 }\end{array}$ \\
\hline
\end{tabular}

ni = não informado; ${ }^{*} 1$ agroindustrial.

Segundo ORTIZ et al. (2002), as mudas de capim-limão devem proceder de banco de plântulas advindo de sementes germinadas a partir de matrizes específicas para esta finalidade. Estas mudas não devem ser submetidas à corte anteriormente ao plantio e ter entre dez a doze meses de desenvolvimento. É aconselhável que o banco de plântulas esteja localizado separadamente do resto da plantação, em pelo menos $1 \mathrm{~km}$, e orientado de tal forma que possa impedir que os ventos predominantes o contaminem com pragas e enfermidades das áreas de cultivo circundantes. Este procedimento, além de garantir a qualidade das mudas, também possibilita a manutenção da diversidade biológica imprescindível para a perpetuação da própria espécie.

\section{Preparo do solo}

A maioria dos produtores informou não realizar análises prévias do solo onde será implantado o cultivo de capim-limão. Apenas alguns 
produtores de Cascavel explicitaram proceder tais análises (Tabela 1).

A metade dos produtores entrevistados demonstrou desconhecer que há necessidade de período de carência de pelo menos dois meses entre correção/ adubação do solo e plantio. Cerca de um terço dos produtores entrevistados indicaram não efetuar prévia adubação das áreas de cultivo.

Segundo os produtores entrevistados, o capim-limão requer solo com $\mathrm{pH}$ em torno de 5,5 , obtido por correção freqüente com calcário. Considerando que não foi registrada informação específica para o capim-limão na literatura, no tocante a $\mathrm{pH}$ e teor de nutrientes, é recomendável que seja sempre realizada avaliação técnica prévia e monitoramento subseqüente que embase orientação agronômica para determinar o correto ajuste dos solos de cultivo.

Segundo CASTRO e CHEMALE (1995), o capim-limão não tolera solos excessivamente úmidos ou demasiadamente secos. Esta planta é esgotante do solo, exigente em matéria orgânica e nutrientes. Por isso, as touceiras devem ser desmanchadas ao fim de três ou cinco anos, no máximo. Para renovar a capacidade nutricional do solo, após a transferência das mudas para outro local, deve-se plantar leguminosas ou plantas de raízes longas. O cultivo de capim-limão exige um esmerado preparo do solo para se obter altos rendimentos de massa verde. Além disso, é preciso facilitar a drenagem interna de solos encharcados.

\section{Época de plantio}

Em cinco dos oito NRA, os produtores paranaenses entrevistados praticavam o plantio de capim-limão entre os meses de agosto a dezembro, pois, segundo estes, a situação climática nesta época é mais favorável para o estabelecimento das mudas e para o desenvolvimento da cultura. Os produtores do Núcleo de Apucarana indicaram realizar o plantio programado, isto é de acordo com a demanda. Já no Núcleo de Ivaiporã evidenciou-se que o plantio era realizado conforme a obtenção de mudas (Tabela 1).

Há divergência na literatura quanto à época ideal de plantio de capim-limão no Brasil. CASTRO e CHEMALE (1995) referenciam os meses de março a abril e fins de agosto a outubro, enquanto que CORRÊA JÚNIOR et al. (1994) indicam setembro a janeiro. Há necessidade, portanto, de estudos de monitoramento e implantação de experimentos de modo a obterem-se informações mais completas sobre a época ideal de plantio com relação à obtenção de maior produção de biomassa e melhor rendimento de óleo essencial.

\section{Espaçamento}

Há divergências na literatura quanto ao espaçamento ideal para capim-limão. Segundo ORTIZ et al. (2002), de modo geral, se a colheita ocorrer entre nove e onze meses após o plantio, o espaçamento recomendado é de $0,90 \times 0,50 \mathrm{~m}$, obtendo-se uma população de 22.000 plantas ha ${ }^{-1}$. Caso a colheita se realize após doze meses do plantio, o espaçamento a empregar é de $1 \times 1 \mathrm{~m}$ para uma população de 10.000 plantas ha ${ }^{-1}$, obtendose um rendimento entre 2 e $2,7 \mathrm{~kg}$ planta ${ }^{-1}$. ACOSTA DE LA LUZ (1993) também recomenda o plantio em sulcos, separados a uma distância de $0,90 \mathrm{~m}$, colocando-se cada perfilho a $0,50 \mathrm{~m}$ um do outro e em qualquer época do ano, de preferência no início do período chuvoso com a finalidade de não regar durante esta etapa. Para CASTRO e CHEMALE (1995) os espaçamentos indicados são 0,60 a 0,80 $\mathrm{m}$ entre linhas e 0,30 a $0,50 \mathrm{~m}$ entre plantas e para OKIDO et al. (2003) o recomendado é $1,0 \mathrm{~m} \times 0,40$ $\mathrm{m}$.

Em sua maioria, os produtores paranaenses realizam o plantio em sulcos, separados a uma distância média de 0,50 a $0,80 \mathrm{~m}$, estando os perfilhos eqüidistantes a $0,50 \mathrm{~m}$, totalizando trinta a quarenta mil mudas por hectare. Quanto à profundidade do sulco de plantação, não se obteve informações junto aos produtores. ORTIZ et al. (2002) recomendam que esta seja de 0,25 a $0,30 \mathrm{~m}$, cobrindo-se a muda até um terço de seu comprimento. Isto permitirá um maior arejamento e, sobretudo, menor número de perfilhos aéreos, que são a causa da fragilidade da planta mãe em touceira (Tabela 1).

\section{Adubação}

$\mathrm{Na}$ maioria das áreas de cultivo pesquisadas, constatou-se a utilização de adubação orgânica (esterco de animais, composto orgânico e húmus de minhoca), porém esta é aplicada de forma não sistemática e sem qualquer orientação técnica. Alguns produtores do NRA de Cascavel informaram que quando utilizam esterco de aviário, a quantidade empregada é de cerca de $4 \mathrm{t} \mathrm{ha}^{-1}$, aplicada uma vez por ano, por ocasião da época de plantio (agostosetembro) (Tabela 1).

A literatura recomenda para a cultura de plantas medicinais, como o capim-limão, o uso de esterco de curral curtido ( 3 a $5 \mathrm{~kg} \mathrm{~m}^{-2}$ ou 30 a $50 \mathrm{tha}$ $\left.{ }^{1}\right)$, esterco de aves (1,5 a $3 \mathrm{~kg} \mathrm{~m}^{-2}$ ou 15 a $\left.30 \mathrm{t} \mathrm{ha}^{-1}\right)$, húmus de minhoca $\left(1,5\right.$ a $3 \mathrm{~kg} \mathrm{~m}^{-2}$ ou 15 a $\left.30 \mathrm{t} \mathrm{ha}^{-1}\right)$ ou composto orgânico, que deve ser repetido anualmente. Estes adubos, em especial húmus de minhoca e esterco de aves, são bastante ricos em nitrogênio, fósforo e potássio (CORRÊA JÚNIOR et al., 1994). Salienta-se a necessidade destes adubos serem previamente muito bem curtidos de modo a evitar a proliferação de bactérias que contaminam as sementes ou mudas (ÁRVORE, 2003). A aplicação de esterco verde não é permitida pelos institutos que fornecem selo de qualidade orgânica, como o Instituto Biodinâmico (IBD, 2003). Adicionalmente, CORRÊA JÚNIOR et al. (1994) recomendam a rotação de cultura com leguminosas, para que a massa incorporada ao solo devolva parte do nitrogênio retirado pela gramínea.

Segundo ORTIZ et al. (2002), o cultivo desta espécie requer importantes quantidades de nitrogênio, fósforo, potássio e matéria orgânica para obterem-se bons rendimentos. Entretanto, caso a finalidade do óleo essencial seja servir de matériaprima para a fabricação de medicamentos, estes elementos não devem ser obtidos pelo uso de fertilizantes inorgânicos e sim pela adubação orgânica, que segundo os autores, é o único meio autorizado em Cuba. Este procedimento implicará no uso de uma quantidade maior por hectare, para suprir as deficiências nutricionais e melhorar as propriedades físicas do solo. Esta adubação deve ser aplicada de forma localizada no sulco, antes da plantação, numa dose de $20 \mathrm{t} \mathrm{ha}^{-1}$. 
Tendo em vista a influência que a adubação orgânica exerce no rendimento de biomassa desta espécie, torna-se necessária a realização de estudos adicionais neste sentido, bem como relacioná-los ao teor de óleo essencial e rendimento de citral obtidos, considerando as condições ambientais do local de cultivo.

\section{Tratos culturais e colheita}

A colheita é realizada manualmente pelos produtores paranaenses. A primeira colheita ocorre, geralmente, entre quatro e oito meses após o plantio e depois são realizadas de duas a cinco vezes ao ano. Alguns produtores do NRA Jacarezinho indicaram que no início do negócio, o excessivo número de cortes praticados em uma determinada área de cultivo (oito a nove por ano), resultou em que a mesma fosse produtiva por apenas dois anos. $O$ corte da folhagem é feito com uso de foice, a cerca de $20 \mathrm{~cm}$ do solo (Tabela 1). Conforme ACOSTA DE LA LUZ (1993) e CASTRO e CHEMALE (1995), este corte deveria ser efetuado entre $10 \mathrm{e} 15 \mathrm{~cm}$ do solo, o que facilita a rebrota. O primeiro corte deveria ser entre seis a oito meses após o plantio, sendo os cortes subseqüentes (no máximo sete), realizados a cada três ou quatro meses.

Segundo os produtores paranaenses entrevistados, a eliminação de ervas daninhas também é procedida de forma manual e não sistemática (Tabela 1). Evidenciou-se que alguns produtores do NRA de Ivaiporã que anteriormente cultivavam capim-limão desistiram do negócio alegando que o excesso de ervas daninhas exigia gastos elevados com herbicidas. Neste sentido, podese inferir que apesar de proibida no contexto de cultivo de plantas medicinais, esta prática ainda pode ocorrer. Ressalta-se que nenhum dos entrevistados admitiu utilizar herbicidas quando diretamente questionado sobre tema.

De acordo com ORTIZ et al. (2002), a primeira capina deve ocorrer entre 20 e 25 dias após o plantio, para a eliminação das ervas daninhas que surgem em conseqüência da umidade do solo neste período. Este manejo pode ser executado com o uso de equipamento com tração animal ou manualmente. Os intervalos deverão ser estabelecidos dependendo do desenvolvimento das plantas e do resultado do controle das ervas daninhas. Estes mesmos autores, considerando que o cultivo desta espécie pode ser submetido à exploração durante vários anos, não recomendam realizar a amontoa durante o primeiro ano. Isto ocorre naturalmente, ao se plantar a muda no fundo do sulco, não permitindo que surjam rebentos aéreos que afetariam o rendimento e o tempo de exploração da área plantada. Após a colheita, deve-se desfazer a amontoa para eliminar certa quantidade de perfilhos e posteriormente, proceder novamente a amontoa, adubação e irrigação.

\section{Irrigação}

De acordo com ORTIZ et al. (2002), a irrigação até os vinte e cinco dias após o plantio representa uma das etapas fundamentais para garantir o êxito do cultivo do capim-limão. Também, recomenda manter a umidade do solo a $85 \%$ até o período de perfilhamento. A partir deste momento, deve-se manter a umidade a $80 \%$ durante todo o período de cultivo. Quando não se dispõe de condições adequadas para irrigação, a plantação deve coincidir com a época de precipitações mais abundantes e freqüentes. Caso haja déficit hídrico em qualquer momento de seu ciclo vegetativo, a plantação manifestará um acelerado necrozamento das folhas mais velhas, começando pelo ápice e abrangendo toda a área foliar, caso este déficit seja mantido. Também CASTRO e CHEMALE (1995), apesar da afirmação que a planta é pouco exigente, recomendam irrigações em períodos de forte seca.

Por outro lado, CORRÊA JÚNIOR et al. (1994) relataram trabalhos indicando aumento no teor de óleo essencial de diversas plantas medicinais quando privadas de irrigação, dentre as quais capimlimão.

Conforme informado pelos produtores entrevistados, o cultivo do capim-limão praticado no Paraná não é irrigado. Talvez isto justifique em parte, tanto o volume de produção obtido, que nem sempre atende as expectativas dos envolvidos, quanto a ocorrência de escurecimento e ressecamento na folhagem, uma reclamação freqüente destes produtores.

\section{Pragas e doenças}

No Paraná, segundo a maioria dos produtores paranaenses entrevistados, a presença de pragas não representa sério problema ao cultivo. Porém, o mesmo não se pode afirmar em relação à ocorrência de doenças, como as fúngicas, que atingem cultivos em seis dos oito Núcleos Produtores (Tabela 1). Segundo os produtores, quando há presença de fungos no cultivo estes afetam tanto a folhagem quanto à raiz, podendo inclusive determinar a morte do vegetal, gerando sérios prejuízos aos produtores. Quando é realizado algum controle, a opção é o método biológico ou químico, este último pelo uso de calda bordaleza, que é eficiente e preconizada pela literatura.

Neste sentido, infere-se que os produtores estão praticando a alternativa correta. Segundo CORRÊA JÚNIOR et al. (1994), o uso de agrotóxicos deixa resíduos que podem alterar os princípios ativos das plantas. Além disso, o mercado de plantas medicinais não aceita produtos com resíduos de agrotóxicos. Desta forma, o controle de pragas, doenças e plantas invasoras deve ser feito por métodos naturais ou físicos e mecânicos, integrados com manejo do solo e nutrição de plantas, dado a estreita relação entre nutrição e sanidade vegetal.

Alguns produtores declararam estar descontentes com a aparência das plantas cultivadas, atribuindo este fato à possibilidade de presença de fungos ou nematóides. Segundo CORRÊA JÚNIOR et al. (1994), nematóides do gênero Meloydogyne são frequentemente relacionados à ocorrência de nodosidades (galhas) nas raízes de gramíneas, prejudicando o desenvolvimento destas plantas. No entanto, as análises nematológicas realizadas revelaram ausência de Meloydogyne sp nos sistemas de raízes e solo avaliados. Por outro lado, detectouse a presença dos gêneros Pratylenchus - agente causador de lesões necróticas em raízes conforme LUCIDCENTRAL (2003) conjuntamente $\mathrm{cm}$ os gêneros Helycotylenchus e Tylenchus - nematóides saprófitas e de duas espécies fitopatogênicas não identificadas. A presença destes patógenos pode estar associada aos problemas observados em campo pelos produtores. 
GOMES, E.C. et al. Caracterização da produção de capim-limão...

CASTRO e CHEMALE (1995) indicam que em locais parcialmente sombreados e nos solos úmidos ocorre o aparecimento de uma ferrugem parda sobre as folhas, fato também evidenciado pelos produtores do Paraná. Entretanto, o agente causal destes sintomas não pode ser identificado.

\section{Parte colhida}

Em todos os oito NRA produtores, as folhas foram citadas como parte colhida, o que está de acordo com o estabelecido pela legislação sanitária brasileira vigente, tanto para finalidade medicamentosa quanto alimentícia (FARMACOPÉIA, 1959; BRASIL, 1998 e 2000).

\section{Rendimento}

O rendimento de biomassa $(\mathrm{kg}$ de folhagem fresca por ha) informado pelos produtores paranaenses variou de 7,5 a 26 tha-1 por ano (Tabela 1). Segundo dados de literatura, em condições adequadas, o rendimento esperado seria de aproximadamente 30 tha-1 por ano (ACOSTA DE LA LUZ, 1993; CASTRO e CHEMALE, 1995). Segundo ORTIZ et al. (2002), em Cuba registram-se valores de rendimento entre 50 e 60 t ha-1 por ano, equivalente a três cortes. A obtenção deste rendimento está atrelada a boas condições de fertilização, irrigação e depende do número de cortes realizados. O mais recomendado seria a realização de quatro colheitas por ano, espaçadas a cada três meses. Este tempo de repouso é necessário para que a planta acumule reservas, possibilitando um rebrote vigoroso.

Para PAREEK e GUPTA (1985) as espécies do gênero Cymbopogon são perenes, e uma vez plantadas fornecerão um rendimento econômico de três a cinco anos, conforme a fertilidade do solo, condições climáticas e a prática fitotécnica empregada. Neste sentido, foi ainda observado em campo, que os produtores dos municípios onde estas condições ocorriam obtiveram os melhores rendimentos, superando inclusive a média acima descrita e por outro lado, o inverso também foi válido.

A produção média de óleo essencial por hectare obtida pelos produtores entrevistados foi de $40 \mathrm{~kg}$. A concentração média de óleo essencial por $100 \mathrm{~g}$ de matéria seca foi igual a $0,6 \%$, valor acima do requerido pela legislação brasileira para comercialização, que exige 0,5\% (BRASIL, 1998). Salienta-se que a obtenção de melhores resultados está associada a diversos fatores, alguns destes relativos ao processo de destilação do óleo (o tempo e a temperatura empregados e o uso de folhas frescas ou secas) e, outros, afetos à colheita da planta, como por exemplo, opção pela colheita na época de maior teor de princípios ativos.

\section{CONCLUSÕES}

Diante das várias inadequações observadas quanto à prática do cultivo do capimlimão no Estado do Paraná, fica evidente a necessidade da elaboração de calendário agrícola adequado às condições locais, que vise a maximização tanto da biomassa quanto do teor de princípios ativos da planta, bem como a sanidade vegetal. Além disso, torna-se imprescindível e urgente, a transferência de informações técnicas aos produtores, visando o conhecimento e aplicação de boas práticas agrícolas na cultura do capim-limão de modo a garantir a melhor qualidade do produto a ser comercializado.

\section{REFERÊNCIAS}

1. ACOSTA DE LA LUZ, L.L. Proporciónese salud cultive plantas medicinales. Havana: Editorial Cientifico-Tecnico, 1993. p. 43-46.

2. ÁRVORE. Adubo orgânico. Disponível em: <http://www.arvore.hpg.com.br/textos/Sement.htm> Acesso em: dez. 2003.

3. BRASIL. Ministério da Saúde. Agência Nacional de Vigilância Sanitária. Portaria da ANVS n. 17 de 24 de fevereiro de 2000. Regulamento técnico sobre o registro de medicamentos fitoterápicos. Diário Oficial da União, Brasília, 25 fev. 2000.

4. BRASIL. Ministério da Saúde. Secretaria de Vigilância Sanitária. Portaria da SVS n. 519 de 26 de junho de 1998. Regulamento técnico para fixação de identidade e qualidade de chás. Diário Oficial da União, Brasília, 29 jun. 1998.

5. CASTRO, L.O.; CHEMALE, M.C. Plantas medicinais, condimentares e condimentares aromáticas: descrição e cultivo. Guaíba: Agropecuária, 1995. $196 \mathrm{p}$.

6. CORRÊA JÚNIOR, C.; MING, L.C.; SCHEFFER, M.C. Cultivo de plantas medicinais, condimentares e aromáticas. 2 ed. Jaboticabal: FUNEP, 1994. 162 p.

7. EVENTO DE EXTENSÃO UNIVERSITÁRIA; Projeto de extensão universitária apoio à utilização de plantas medicinais pela rede de saúde de municípios do Paraná, Morretes. Folder. UFPR, 2000.

8. $\quad$ FARMACOPÉIA dos Estados Unidos do Brasil. 2. ed. São Paulo: Siqueira, 1959. 606 p.

9. GOMES, E.C. Capim-limão- Cymbopogon citratus (D.C.) Stapf: subsídios para melhoria de qualidade do cultivo, industrialização e comercialização no Estado do Paraná. Curitiba, 2003. 184 f. Tese (Doutorado em Agronomia) - Setor de Ciências Agrárias, Universidade Federal do Paraná.

10. IBD. Instituto Biodinâmico. Adubo orgânico. Disponível em: <www.ibd.com.br> Acesso em dez.2003.

11. LUCIDCENTRAL. Nematodes. Disponível em: <http//www.lucidcentral.com> Acesso em ago.2003.

12. OKIDO, C.T.; BARBOSA, J.P.R.A.D; BÉBER, L.M.; MALUF, W. R. Hortas medicinais: opção de renda e fonte de cura. Boletim Técnico de Hortaliças, n. 70, 2002.

13. ORTIZ, R.S; MARRERO, G.V.; NAVARRO, A.L.T. Instructivo técnico del cultivo de Cymbopogon citratus (D.C) Stapf (caña santa). Revista de Plantas Medicinales, Havana, v. 7, n. 2, 2002.

14. PARANÁ. Secretaria de Estado da Agricultura e do Abastecimento. Departamento de Economia Rural. Divisão de Estatísticas Básicas. Relação área e produção de capim-limão safra 00/01 à 03/04. Disponível em < http:// www.pr.gov.br/seab > Acesso em mar. 2005.

15. PAREEK, S.K.; GUPTA, R. On the status of agronomic research in Cymbopogon grasses in India with projections on the future work. Indian Perfumer, v. 29, n. 3-4, p. 215-224, 1985.

16. SILVA JÚNIOR, A.A. VIZZOTTO, V.J., GIORGI, E. et al. Plantas medicinais, caracterização e cultivo. Florianópolis: EPAGRI, 1994. 71 p. (EPAGRI. Boletim técnico, 68). 